\title{
FAKTOR-FAKTOR YANG MEMPENGARUHI PEMBERIAN ASI EKSKLUSIF DI WILAYAH KERJA PUSKESMAS KOTA BOGOR TAHUN 2019
}

\author{
Enih Maryanih ${ }^{1}$, Husnah Maryati ${ }^{2}$, Indira Chotimah ${ }^{3}$ \\ ${ }^{1}$ Mahasiswa Konsentrasi Manajemen Pelayanan Kesehatan, Program Studi Kesehatan Masyarakat, Fakultas Ilmu \\ Kesehatan, Universitas Ibn Khaldun Bogor. Jl. K.H Sholeh Iskandar Raya Km. 2, Kedung Badak, Bogor 16162, Jawa \\ Barat. Email : enih@gmail.com \\ ${ }^{2}$ Dosen Program Studi Kesehatan Masyarakat, Fakultas Ilmu Kesehatan, Universitas Ibn Khaldun Bogor. Jl. K.H \\ Sholeh Iskandar Raya Km. 2, Kedung Badak, Bogor 16162, Jawa Barat. Email : $\underline{\text { husnah@gmail.com }}$ \\ ${ }^{3}$ Dosen Program Studi Kesehatan Masyarakat, Fakultas Ilmu Kesehatan, Universitas Ibn Khaldun Bogor. Jl. K.H \\ Sholeh Iskandar Raya Km. 2, Kedung Badak, Bogor 16162, Jawa Barat. Email : indira.chotimah@gmail.com
}

\begin{abstract}
Abstrak
ASI Eksklusif adalah pemberian ASI tanpa makanan dan minuman tambahan lain pada bayi berumur nol sampai enam bulan. Penelitian ini bertujuan untuk mengetahui tentang Faktor Faktor Yang Mempengaruhi Pemberian ASI Eksklusif di wilayah kerja Puskesmas Mekarwangi Kota Bogor Desain penelitian yang digunakan adalah deskriptif, dengan populasi berjumlah 796 bayi dari data di wilayah kerja Puskesmas Mekarwangi Kota Bogor pada bulan oktober 2019. Teknik sampling yang di gunakan adalah purposive sampling dengan jumlah sampel 89 responden. Alat pengumpulan data berupa kuesioner, dan teknik analisa data menggunakan cross sectional. Dari hasil penelitian terhadap 89 responden didapatkan faktor yang mempengaruhi pemberian ASI Eksklusif yaitu adanya faktor usia 59 responden (66,3\%), faktor pendidikan 59 responden (66,3\%), faktor pekerjaan 71 responden $(79,8 \%)$, faktor penghasilan 48 responden (53,9\%), faktor pengetahuan 58 responden (65,2\%), faktor sikap 58 responden $(65,2 \%)$, faktor perilaku 61 responden $(68,5 \%)$, dan faktor riwayat pemberian ASI 85 responden (95,5\%). Hasil penelitian merekomendasi untuk penelitian selanjutnya diharapkan menindak lanjuti faktor-faktor yang mempengaruhi pemberian ASI Eksklusif.

Kata kunci :ASI Eksklusif, makanan dan minuman tambahan, Teknik sampling.
\end{abstract}

\section{PENDAHULUAN}

Angka Kematian Bayi menurut Sustainanble Depelovment Goals (SDGs) tahun 2015 berjumlah 40 per 1000 kelahiran hidup dan masih menempati peringkat ke-4 tertinggi kematian bayi se- ASEAN. Angka kematian bayi (AKB) adalah jumlah kematian bayi dalam usia 28 hari pertama kehidupan per 1.000 kelahiran hidup (Kementerian Kesehatan RI, 2015) Penyebab kematian bayi terbesar di Indonesia adalah kematian neonatal dan dua pertiga dari kematian neonatal adalah pada satu minggu pertama dimana daya imun bayi masih sangat rendah. Angka kematian bayi yang cukup tinggi dapat dihindari dengan pemberian air susu ibu (ASI).

Banyak penelitian yang dilakukan, tehnologi canggih digunakan, namun tindakan preventif yang paling ampuh dilakukan untuk menyelamatkan bayi-bayi Indonesia adalah melakukan Inisiasi Menyusui Dini (IMD) dan memberikan ASI eksklusif (Moascara, 2011). Beberapa faktor yang menyebabkan bayi tidak diberikan ASI dengan baik. Faktor tersebut 
adalah faktor karakteristik ibu, faktor bayi, lingkungan, dukungan keluarga, pendidikan kesehatan, sosial ekonomi dan budaya (Budiharjo, 2013).

Pengetahuan, sikap, dan motivasi ibu masih menjadi faktor-faktor utama perilaku pemberian ASI eksklusif. Selain itu, dukungan keluarga baik orang tua, mertua, dan suami, serta dukungan tenaga kesehatan masih menjadi faktor eksternal penting dalam pemberian ASI secara eksklusif. Saya menyajikan temuan dari sejumlah riset yang menjelaskan rendahnya cakupan ASI eksklusif tersebut.

Pemberian ASI eksklusif berarti hanya menjadikan ASI sebagai makanan bayi hingga usia 6 bulan, tanpa tambahan apapun, termasuk air minum dan susu formula. Namun dalam keadaan mendesak, diperbolehkan memberi vitamin, mineral, dan obat-obatan kepada bayi. Selain itu, terdapat kondisi medis tertentu, baik pada ibu maupun bayi, yang memperbolehkan pemberian susu formula untuk memenuhi nutrisi bayi. Sifat ASI yang kaya nutrisi dan mencegah bayi dari gizi buruk dan stunting telah diketahui oleh sebagian besar ibu. Terutama yang bekerja sebagai tenaga kesehatan. Selain memiliki pengetahuan yang baik, umumnya tenaga kesehatan memiliki sikap yang positif terhadap ASI eksklusif. Namun, penelitian di Kota Bandar Lampung pada 2017 menunjukkan bahwa tidak semua tenaga kesehatan, hanya 57,4\%, memberikan ASI secara eksklusif

kepada bayinya, Pemberian ASI eksklusif tidak hanya mengandalkan pengetahuan dan sikap positif. Ketersediaan fasilitas dan waktu untuk memberikan ASI pada bayi menjadi hal lain yang perlu dipertimbangkan. Besarnya campur tangan keluarga dalam perawatan bayi juga mempengaruhi ibu dalam praktik pemberian ASI eksklusif ini.

World Health Organization (WHO) menyatakan bahwa ASI adalah air susu ibu yang diberikan kepada bayi sejak dilahirkan selama 6 (enam) bulan tanpa menambahkan dan/atau mengganti dengan makanan atau minuman lain. UNICEF menyatakan bahwa sebanyak 30.000 kematian bayi di Indonesia dan 10 juta kematian balita di dunia pada setiap tahunnya, bisa dicegah dengan pemberian ASI secara eksklusif selama 6 bulan sejak tanggal kelahirannya tanpa harus memberikan makanan dan minuman tambahan kepada bayi. UNICEF, Organisasi

Kesehatan Dunia (WHO) dan Kementerian Kesehatan merekomendasikan bahwa bayi disusui segera setelah lahir dan tidak diberi makanan apapun selain ASI selama 6 bulan pertama kehidupan, tidak diberikan air, ataupun makanan lain, hanya ASI saja. Dari 6 bulan hingga setidaknya 2 tahun, ASI harus tetap diberikan bersama dengan makanan pendamping ASI yang aman dan bergizi. Namun di Indonesia, meskipun sejumlah perempuan sebesar 96\% menyusui anak mereka dalam kehidupan mereka, hanya $42 \%$ dari bayi yang berusia di bawah 6 bulan yang mendapatkan ASI eksklusif. Pada saat anak-anak mendekati ulang tahunnya yang ke dua, hanya 55\% yang masih diberi ASI.

Cakupan program ASI eksklusif di Indonesia sangat fluktuatif. Data Survey Demografi Indonesia (SDKI) 1997-2007 menyebutkan bahwa prevalensi ASI eksklusif turun dari 40,2\% menjadi 39,5\% pada tahun 1997 dan 32\% pada tahun 2007, hasil laporan sementara hasil Survey Demografi Indonesia tahun 2012 sebesar 42\% dan tahun 2013 hanya mencapai 32,2\%. Kesadaran para ibu untuk memberikan Air Susu Ibu (ASI) Esklusif di Kota Bogor masih rendah. Hasil survei yang dilakukan Dinas Kesehatan Kota Bogor mengungkapkan dari sekitar 9.000 ibu-ibu menyusui di kota itu, hanya 20\% yang menyusui anaknya tanpa memberikan makanan lainnya pada usia 6 bulan pertama sang bayi. 


\section{METODE PENELITIAN}

Penelitian ini menggunakan metode penelitian kuantitatif dengan desain penelitian cross sectional yaitu

\section{HASIL PENELITIAN}

Hasil Analisis Univariat Analisis univariat pada penelitian terdiri dari karakteristik responden, Pengetahuan, Sikap, studi yang mempelajari prevalensi, distribusi, maupun hubungan umur, pendidikan, pekerjaan, pengetahuan, sikap, ekonomi dengan pemberian ASI Eksklusif (faktor penelitian) dengan cara mengamati status pemberian ASI Eksklusif, atau karakteristik terkait kesehatan lainnya, secara serentak pada individu-individu dari suatu populasi pada satu saat (Notoatmodjo, 2010). Data kuantitatif dilakukan dengan metode survei, yaitu melalui kuesioner sebagai instrumen utama penelitian. Rancangan penelitian ini digunakan untuk mengetahui factorfaktor yang mempengaruhi pemberian ASI Eksklusif di Wilayah Kerja Puskesmas Mekarwangi Kota Bogor Tahun 2019.

Perilaku, Riwayat Pemberian ASI.

- Karakteristik responden Analisis univariat dari karakteristik responden meliputi nomor responden, umur responden, pendidikan terakhir responden, pekerjaan responden, jumlah keseluruhan anak, jumlah bayi, usia anak terakhir dan penghasilan responden.

Tabel 1. Distribusi Responden Berdasarkan Usia

\begin{tabular}{llc}
\hline Usia & Frekuensi & \% \\
\hline 20-25 tahun & 59 & 66,3 \\
\hline 26-30 tahun & 30 & 33,7 \\
\hline Total & 89 & 100
\end{tabular}

Berdasarkan tabel 1 diketahui bahwa umur responden lebih banyak yang berusia 20-25 tahun yaitu berjumlah 59 responden (66,3\%), sedangkan responden yang berusia 26-30 tahun berjumlah 30 responden $(33,7 \%)$.

Tabel 2. Distribusi Responden Berdasarkan Pendidikan

\begin{tabular}{lcc}
\hline Pendidikan & Frekuensi & \% \\
\hline SD & 2 & 2,2 \\
\hline SLTP & 12 & 13,5 \\
\hline SLTA & 59 & 66,3 \\
\hline Perguruan tinggi & 16 & 18,0 \\
\hline Total & 89 & 100
\end{tabular}

Berdasarkan tabel 2 diketahui bahwa pendidikan terakhir responden lebih banyak pendidikan SLTA yaitu berjumlah 59 responden (66,3\%), sedangkan pendidikan perguruan tinggi berjumlah 16 responden (18,0\%), pendidikan SLTP berjumlah 12 responden (13,5\%), dan pendidikan SD berjumlah 2 responden $(2,2 \%)$. 
Tabel 3. Distribusi Responden Berdasarkan Pekerjaan

\begin{tabular}{lcc}
\hline Pekerjaan & Frekuensi & \% \\
\hline Tidak Bekerja & 71 & 79,8 \\
\hline Bekerja & 18 & 20,2 \\
\hline Total & 89 & 100
\end{tabular}

Berdasarkan tabel 3 diketahui bahwa berdasarkan pekerjaan responden lebih banyak Tidak Bekerja yaitu berjumlah 71 responden (79,8\%), sedangkan responden yang Bekerja berjumlah 18 responden $(20,2 \%)$.

Tabel 4 Distribusi Responden Berdasarkan Jumlah Anak

\begin{tabular}{lcc}
\hline Jumlah anak & Frekuensi & $\mathbf{\%}$ \\
\hline $1-2$ & 83 & 93,3 \\
\hline $3-4$ & 6 & 6,7 \\
\hline Total & 89 & 100
\end{tabular}

Berdasarkan tabel 4 diketahui bahwa jumlah anak lebih banyak 1-2 yaitu berjumlah 83 responden (93,3\%), dan jumlah anak 3-4 berjumlah 6 responden(6,7\%).

Tabel 5. Distribusi Responden Berdasarkan Jumlah Bayi

\begin{tabular}{lcl}
\hline Jumlah bayi & Frekuensi & $\mathbf{\%}$ \\
\hline 1 & 86 & 96,6 \\
\hline 2 & 3 & 3,4 \\
\hline Total & 89 & 100
\end{tabular}

Berdasarkan tabel 5 diketahui bahwa jumlah bayi lebih banyak 1 yaitu berjumlah 86 responden $(96,6 \%)$, dan jumlah bayi 2 Berjumlah 3 responden $(3,4 \%)$.

Tabel 6. Distribusi Responden Berdasarkan Usia Anak Terakhir

\begin{tabular}{lcc}
\hline Usia anak terakhir & Frekuensi & \% \\
\hline 0-6 bulan & 21 & 23,6 \\
\hline 7 bulan- 1 tahun & 12 & 13,5 \\
\hline$>1$ tahun & 56 & 62,9 \\
\hline Total & 89 & 100
\end{tabular}

Berdasarkan tabel 5.13 diketahui bahwa usia anak terakhir lebih banyak $>1$ tahun yaitu berjumlah 56 responden (62,9\%), sedangkan usia anak terakhir 0-6 bulan berjumlah 21 responden $(23,6 \%)$, dan usia anak terakhir 7 bulan-1 tahun berjumlah12 responden $(13,5 \%)$.

Tabel 7. Distribusi Responden Berdasarkan Penghasilan

\begin{tabular}{lll}
\hline Penghasilan & Frekuensi & $\mathbf{\%}$ \\
\hline Tidak Mampu & 9 & 10,1 \\
\hline Mampu & 80 & 89,9 \\
\hline Total & 89 & 100
\end{tabular}


Berdasarkan tabel 7 diketahui bahwa berdasarkan penghasilan responden lebih banyak yang Mampu yaitu berjumlah 80 responden (89,9\%), sedangkan yang Tidak Mampu yaitu berjumalh 9 responden $(10,1)$.

- $\quad$ Variabel Independen

Tabel 8. Distribusi Responden Berdasarkan Pengetahuan

\begin{tabular}{lll}
\hline Pengetahan & Frekuensi & $\%$
\end{tabular}

\begin{tabular}{lcc}
\hline Kurang baik & 31 & 34,8 \\
\hline Baik & 58 & 65,2 \\
\hline Total & 89 & 100
\end{tabular}

Berdasarkan tabel 8 Diketahui bahwa pengetahuan responden lebih banyak yang baik yaitu berjumlah 58 responden $(65,2 \%)$, dan pengetahuan responden yang kurang baik berjumlah 31 responden $(34,8 \%)$.

Tabel 9. Distribusi Responden Berdasarkan Sikap

\begin{tabular}{lcc}
\hline Sikap & Frekuensi & \% \\
\hline Kurang baik & 31 & 34,8 \\
\hline Baik & 58 & 65,2 \\
\hline Total & 89 & 100
\end{tabular}

Berdasarkan tabel 9 diketahui bahwa sikap responden lebih banyak yang baik yaitu berjumlah 58 responden $(65,2 \%)$, dan sikap responden yang kurang baik berjumlah 31 responden $(34,8 \%)$.

Tabel 10. Distribusi Responden Berdasarkan Perilaku

\begin{tabular}{lcc}
\hline Perilaku & Frekuensi & \% \\
\hline Kurang baik & 28 & 31,5 \\
\hline Baik & 61 & 68,5 \\
\hline Total & 89 & 100
\end{tabular}

Berdasarkan tabel 10 diketahui bahwa perilaku responden lebih banyak yang baik yaitu berjumlah 61 responden (68,5\%), dan perilaku responden yang kurang baik berjumlah 28 responden $(31,5 \%)$. 
- Variabel Dependen

Tabel 11. Distribusi Responden Berdasarkan Riwayat Pemberian ASI

\begin{tabular}{lcc}
\hline Riwayat pemberian ASI & Frekuensi & \% \\
\hline Tidak & 4 & 4,5 \\
\hline Ya & 85 & 95,5 \\
\hline Total & 89 & 100
\end{tabular}

Berdasarkan tabel 11 diketahui bahwa riwayat pemberian ASI lebih banyak yang menjawab ya yaitu berjumlah 85 responden (95,5\%), dan riwayat pemberian ASI yang menjawab tidak berjumlah 4 responden $(4,5 \%)$.

- Analisis Bivariat

Analisis bivariat pada penelitian ini terdiri dari hubungan umur dengan riwayat pemberian asi, hubungan pendidikan dengan riwayat pemberian asi, hubungan pekerjaan dengan riwayat pemberian asi, hubungan penghasilan dengan riwayat pemberian asi, hubungan pengetahuan dengan riwayat pemberian asi, hubungan sikap dengan riwayat pemberian asi, dan hubungan perilaku dengan riwayat pemberian asi.

Dapat diketahui bahwa hubungan umur terhadap riwayat pemberian asi adalah sebanyak 59 responden yang berumur 20-25 tahun yaitu sebanyak 57 responden yang memberikan asi dan 2 responden tidak memberikan asi. Sedangkan umur terhadap riwayat pemberian asi adalah sebanyak 30 responden yang berumur 26- 30 tahun yaitu sebanyak 28 responden yang memberikan asi dan 2 responden yang tidak memberikan asi.

Dari hasil uji statistik maka diperoleh nilai Pvalue $=0,601$ sehingga nilai $p>\alpha(0,05)$, maka dapat disimpulkan bahwa Ho diterima dan Ha ditolak sehingga tidak ada hubungan antara umur dengan riwayat pemberian ASI pada responden yang berumur 20-25 tahun dan tidak ada hubungan antara umur dengan riwayat pemberian ASI pada responden yang berumur 26- 30 tahun.

Dapat diketahui bahwa hubungan pendidikan terhadap riwayat pemberian asi adalah sebanyak 2 responden yang berpendidikan SD yaitu sebanyak 2 responden yang memberikan asi dan 0 responden tidak memberikan asi. Hubungan pendidikan terhadap riwayat pemberian asi adalah sebanyak 12 responden yang berpendidikan SLTP yaitu sebanyak 11 responden yang memberikan asi dan 1 responden tidak memberikan asi. Hubungan pendidikan terhadap riwayat pemberian asi adalah sebanyak 59 responden yang berpendidikan SLTA yaitu sebanyak 59 responden yang memberikan asi dan 0 responden tidak memberikan asi.Sedangkan pendidikan terhadap riwayat pemberian asi adalah sebanyak 16 responden yang berpendidikan perguruan tinggi yaitu sebanyak 13 responden yang memberikan asi dan 3 responden yang tidak memberikan asi.

Dapat diketahui bahwa hubungan pekerjaan terhadap riwayat pemberian asi adalah sebanyak 18 responden yang bekerja yaitu sebanyak 16 responden yang memberikan asi dan 2 responden tidak memberikan asi. Sedangkan pekerjaan terhadap riwayat pemberian asi adalah sebanyak 71 responden yang tidak bekerja yaitu sebanyak 69 responden yang memberikan asi dan 2 responden yang tidak memberikan asi. 
Dari hasil uji statistik maka diperoleh nilai Pvalue $=0,181$ sehingga nilai $\mathrm{p}>\alpha(0,05)$, maka dapat disimpulkan bahwa Ho diterima dan Ha ditolak sehingga tidak ada hubungan antara pekerjaan dengan riwayat pemberian ASI pada responden yang bekerja dan tidak ada hubungan antara pekerjaan dengan riwayat pemberian ASI pada responden yang tidak bekerja.

Dapat diketahui bahwa hubungan penghasilan terhadap riwayat pemberian asi adalah sebanyak 80 responden yang mampu yaitu sebanyak 76 responden yang memberikan asi dan 4 responden tidak memberikan asi. Sedangkan penghasilan terhadap riwayat pemberian asi adalah sebanyak 9 responden yang tidak mampu yaitu sebanyak 9 responden yang memberikan asi dan 0 responden yang tidak memberikan asi.

Dari hasil uji statistik maka diperoleh nilai Pvalue $=1,000$ sehingga nilai $p>\alpha(0,05)$, maka dapat disimpulkan bahwa Ho diterima dan Ha ditolak sehingga tidak ada hubungan antara penghasilan dengan riwayat pemberian ASI pada responden yang mampu dan tidak ada hubungan antara penghasilan dengan riwayat pemberian ASI pada responden yang tidak mampu.

Dapat diketahui bahwa hubungan pengetahuan terhadap riwayat pemberian asi adalah sebanyak 58 responden yang berpengetahuan baik yaitu sebanyak 54 responden yang memberikan asi dan 4 responden tidak memberikan asi. Sedangkan pengetahuan terhadap riwayat pemberian asi adalah sebanyak 31 responden yang berpengetahuan kurang baik yaitu sebanyak 31 responden yang memberikan asi dan 0 responden yang tidak memberikan asi.

Dari hasil uji statistik maka diperoleh nilai Pvalue $=0,293$ sehingga nilai $p>\alpha(0,05)$, maka dapat disimpulkan bahwa Ho diterima dan Ha ditolak sehingga tidak ada hubungan antara pengetahuan dengan riwayat pemberian ASI pada responden yang berpengetahuan baik dan tidak ada hubungan antara pengetahuan dengan riwayat pemberian ASI pada responden yang berpengetahuan kurang baik.

Dapat diketahui bahwa hubungan sikap terhadap riwayat pemberian asi adalah sebanyak 58 responden yang bersikap baik yaitu sebanyak 55 responden yang memberikan asi dan 3 responden tidak memberikan asi. Sedangkan sikap terhadap riwayat pemberian asi adalah sebanyak 31 responden yang bersikap kurang baik yaitu sebanyak 30 responden yang memberikan asi dan 1 responden yang tidak memberikan asi.

Dari hasil uji statistik maka diperoleh nilai Pvalue $=1,000$ sehingga nilai $p>\alpha(0,05)$, maka dapat disimpulkan bahwa Ho diterima dan Ha ditolak sehingga tidak ada hubungan antara sikap dengan riwayat pemberian ASI pada responden yang bersikap baik dan tidak ada hubungan antara sikap dengan riwayat pemberian ASI pada responden yang bersikap kurang baik.

Dapat diketahui bahwa hubungan perilaku terhadap riwayat pemberian asi adalah sebanyak 61 responden yang berperilaku baik yaitu sebanyak 61 responden yang memberikan asi dan 0 responden tidak memberikan asi.Sedangkanperilaku terhadap riwayat pemberian asi adalah sebanyak 28responden yang berperilaku kurang baik yaitu sebanyak 24 responden yang memberikan asi dan 4 responden yang tidak memberikan asi.

Dari hasil uji statistik maka diperoleh nilai Pvalue $=0,008$ sehingga nilai $p<\alpha(0,05)$, maka dapat disimpulkan bahwa Ho ditolak dan Ha diterima sehingga ada hubungan antara 
perilaku dengan riwayat pemberian ASI pada responden yang berprilaku baik dan ada hubungan antara perilaku dengan riwayat pemberian ASI pada responden yang berperilaku kurang baik.

\section{KESIMPULAN DAN SARAN}

\section{- Kesimpulan}

Berdasarkan hasil penelitian yang telah dilakukan di Wilayah Kerja Puskesmas Mekarwangi Kota Bogor dan penjelasan yang telah diuraikan sebelumnya maka dapat ditarik kesimpulan sebagai berikut:

- Hasil analisis chi square antara umur dengan riwayat pemberian ASI pada responden umur 20- 30 tahun menunjukkan nilai signifikansi dari penelitian ini adalah sebesar 0,601 dan lebih besar dari nilai $\alpha(0,05)$. Maka tidak adanya hubungan antara umur dengan riwayat pemberian ASI, sehingga hipotesis penelitian ini ditolak.

- Hasil analisis chi square antara pendidikan dengan riwayat pemberian ASI pada responden pendidikan SD-Perguruan Tinggi menunjukkan nilai signifikansi dari penelitian ini adalah sebesar 0,601 dan lebih besar dari nilai $\alpha(0,05)$. Maka tidak adanya hubungan antara umur dengan riwayat pemberian ASI, sehingga hipotesis penelitian ini ditolak.

- Hasil analisis chi square antara pekerjaan dengan riwayat pemberian ASI pada responden yang bekerja dan tidak bekerja menunjukkan nilai signifikansi dari penelitian ini adalah sebesar 0,181 dan lebih besar dari nilai $\alpha(0,05)$. Maka tidak adanya hubungan antara pekerjaan dengan riwayat pemberian ASI, sehingga hipotesis penelitian ini ditolak.

- Hasil analisis chi square antara penghasilan dengan riwayat pemberian ASI pada responden yang berpenghasilan mampu dan kurang mampu menunjukkan nilai signifikansi dari penelitian ini adalah sebesar 1,000 dan lebih besar dari nilai $\alpha(0,05)$. Maka tidak adanya hubungan antara penghasilan dengan riwayat pemberian ASI, sehingga hipotesis penelitian ini ditolak.

- Hasil analisis chi square antara pengetahuan dengan riwayat pemberian ASI pada responden yang berpengetahuan baik dan kurang baik menunjukkan nilai signifikansi dari penelitian ini adalah sebesar 0,293 dan lebih besar dari nilai $\alpha(0,05)$. Maka tidak adanya hubungan antara pengetahuan dengan riwayat pemberian ASI, sehingga hipotesis penelitian ini ditolak.

- Hasil analisis chi square antara sikap dengan riwayat pemberian ASI pada responden yang bersikap baik dan kurang baik menunjukkan nilai signifikansi dari penelitian ini adalah sebesar 1,000 dan lebih besar dari nilai $\alpha(0,05)$. Maka tidak adanya hubungan antara sikap dengan riwayat pemberian ASI, sehingga hipotesis penelitian ini ditolak.

- Hasil analisis chi square antara perilaku dengan riwayat pemberian ASI pada responden berperilaku baik dan kurang baik menunjukkan nilai signifikansi dari penelitian ini adalah sebesar 0,008 dan lebih kecil dari nilai $\alpha(0,05)$. Maka adanya hubungan antara perilaku dengan riwayat pemberian ASI, sehingga hipotesis penelitian ini diterima.

\section{- Saran}

\section{Bagi Puskesmas}

- Hasil penelitian diharapkan dapat menjadi masukan dalam melakukan perbaikan sekaligus meningkatkan mutu pelayanan kesehatan ,masyarakat.

- Perlu adanya monitoring dan evaluasi terkait adanya kegiatan pemberian PMT ASI berupa 
biskuit dan susu kotak yang merupakan donasi dari perusahaan agar pemberiannya dibatasi dan tepat sasaran dalam setiap kegiatan posyandu di Wilayah Kerja Puskesmas Mekar Wangi Kota Bogor sehingga tidak mempengaruhi perilaku ibu dalam memberikan ASI Eksklusif.

- Perlu adanya kebijakan dari puskesmas kepada setiap posyandu agar buku KIA yang selama ini disimpan di posyandu di kembalikan kepada pemiliknya agar buku tersebut bisa dimanfaatkan oleh ibu untuk memperoleh pengetahuan terkait menyusui. Serta menambahkan sesi penyuluhan dalam setiap kegiatan posyandu agar manfaat ASI dapat tersampaikan kepada ibu menyusui. Sehingga ibu lebih termotivasi untuk melakukan pemberian ASI Eksklusif kepada bayinya.

\section{Bagi ibu dan keluarga}

Begitu pentingnya manfaat dari pemberian ASI Eksklusif, maka penting bagi ibu yang melahirkan perlu untuk memberikan ASI Eksklusif kepada bayinya. Untuk meningkatkan kesadaran ibu dalam hal tersebut, maka hal yang dapat dilakukan adalah:

- Selama kehamilan, ibu perlu aktif melakukan konsultasi bidan yang melakukan pemeriksaan kehamilannya guna memperoleh informasi terkait menyusui dan mendapat motivasi dari tenaga kesehatan untuk terus melakukan pemberian ASI Eksklusif kepada bayinya.

- Selama kehamilan, penting bagi keluarga terutama suami untuk terus mendampingi ibu saat melakukan konsultasi kehamilan dengan bidan. Sehingga setelah kelahiran bayi, suami dapat memberikan dukungan kepada ibu untuk memberikan ASI Eksklusif kepada bayinya karena suami merupakan individu terdekat bagi ibu menyusui.

\section{Bagi Peneliti Selanjutnya}

- Berdasarkan informasi yang diperoleh dalam hasil ini diharapkan agar penelitian selanjutnya dapat menganalisis faktor-faktor lainnya yang belum diteliti yang mungkin dapat berhubungan dengan pemberian ASI Eksklusif yang tidak tergambarkan dalam penelitian ini dengan desain studi yang berbeda dan jumlah sampel yang lebih banyak.

- Peneliti selanjutnya harus lebih teliti dalam memodifikasi kuesioner penelitian.

\section{DAFTAR PUSTAKA}

Afidah, Nur. 2012. (Analisis Sistem Manajemen Program Pemberian Asi Eksklusif di Wilayah Kerja Puskesmas Candilama Kota Semarang). Jurnal Kesehatan Masyarakat.

Amir, Aswita, Nursalim, Aliffiani Widyansyah. 2018. (Faktor-Faktor Yang Mempengaruhi Pemberian ASI Pada Bayi Neonatal Di RSIA Pertiwi Makassar). Alumni Prodi D-IV, Jurusan Gizi, Politeknik Kesehatan Kemenkes, Makassar.

Arifati, Nurce. 2017. (Analisis Faktor Yang Mempengaruhi Pemberian Asi Eksklusif Pada Bayi

Di Kelurahan Warnasari Kecamatan Citangkil Kota Cilegon). STIKES Faletehan Serang Banten.

Astuti, Isroni. 2013. (Determinan Pemberian ASI Eksklusif Pada Ibu Menyusui). Dosen Jurusan Kebidanan Poltekes Kemenkes Jakarta 1.

Chotimah, I., Oktaviani, S., \& Madjid, A. (2018). Evaluasi Program Tb Paru Di Puskesmas Belong Kota Bogor Tahun 2018. PROMOTOR, 1(2), 87-95.

Chotimah, I., Anggraini, D. (2018). Pemberdayaan Masyarakat Melalui Peningkatan Kualitas

Pendidikan, Ekonomi, Kesehatan Dan Lingkungan. ABDIDOS 2 (1), 62-72.

Chotimah, I. (2017). Gambaran Perilaku Merokok Mahasiswa Universitas Ibn Khaldun Bogor 


\section{HEARTY 5 (1).}

Dian Pangesti, Kharisma. 2015. (Gambaran Pemberian Air Susu Ibu Pada Ibu Dengan Bayi Usia 6-12 Bulan Di Desa Kadilangu Kecamatan Bakti Kabupaten Sukoharjo). Fakultas Ilmu Kesehatan Universitas Muhammadiyah Surakarta.

Fikawati, Sandra, Ahmad Syafiq. 2010. (Kajian Implementasi Dan Kebijakan Air Susu Ibu Eksklusif Dan Inisiasi Menyusui Dini Di Indonesia). Pusat Kajian Gizi Dan Kesehatan, Fakultas Kesehatan Masyarakat, Universitas Indonesia, Depok 16424, Indonesia.

Fitriani. 2017. (Fungsi Manajemen Dalam Pelaksanaan Program ASI Eksklusif Di Puskesmas Jeuram Kabupaten Nagan Raya). Fakultas Kesehatan Masyarakat, Universitas Teuku Umar, Aceh Barat-Indonesia.

Isnawati, Dina. 2018. (Gambaran Pemberian ASI Eksklusif Pada Pekerja Wanita Di CV. Media Printika Kabupaten Sleman. Program Kebidanan Program Sarjana Terapan Fakultas Ilmu Kesehatan Universitas 'Aisyiyah Yogyakarta.

Jaljuli. 2007. (Faktor-Faktor Yang Berpengaruh Terhadap Kelangsungan Pemberian ASI Eksklusif Di Tiga Kabupaten Cirebon,Cianjur,Ciamis Provinsi Jawa Barat Tahun 2003. Analisis Survey Data Dasar Asuh-KAP 2). TESTI. FKM-UI.

Kartika. 2015. (Hubungan Lamanya Jam Kerja Ibu Menyusui Dengan Pemberian ASI Pada Bayi

0-6 Bulan Di Desa Bangsir Kecamatan Bangsir Kabupaten Jepara). Jurnal Kesehatan Dan Budaya.

https://scholar.google.co.id/scholar?q=masalah+asi+eksklusif+menurut+who\&hl=id\&a

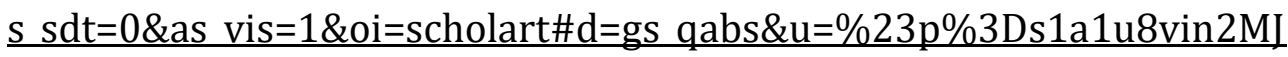

Prasetya, E. (2018). Pemberdayaan Masyarakat Tentang Kesehatan, Pendidikan dan Kreatifitas. Abdi Dosen: Jurnal Pengabdian Pada Masyarakat 2 (1), 19-25.

Rahmawati, Meiyana Dianning. 2010. (Faktor-Faktor Yang Mempengaruhi Pemberian ASI Eksklusif Pada Ibu Menyusui Di Kelurahan Pedalangan Kecamatan Banyumanik Kota Semarang). Staf Pengajar Program Studi D-III Keperawatan STIKES Kusuma Husada Surakarta.

Roesli, Utami. 2005. (Mengenal ASI Eksklusif). Jakarta : Tubulus Agriwidya

Sanda. 2011. (Gambaran Pengetahuan, Pekerjaan Dan Dukungan Keluarga Terhadap Pemberian ASI Eksklusif pada bayi Umur 6-11 bulan di Puskesmas Antang Perumnas Kota Makasar). Jurnal Fakultas Kesehatan Masyarakat Universitas Hasanudin Makasar. (Online 7 Februari 2015): www.unhas.ac.id/ha ndle/5546/Jurnal.pdf.

Siregar, Arifin. 2004. (Pemberian ASI Eksklusif Dan Faktor - Faktor Yang Mempengaruhinya). Gizi Kesehatan Masyarakat Fakultas Kesehatan Masyarakat Universitas Sumatera Utara.

Sihombing, Setia. 2018. (Hubungan Pekerjaan Dan Pendidikan Ibu Dengan Pemberian Asi Eksklusif Di Wilayah Kerja Puskesmas Hinai Kiri). Jurnal Bidan "Midwife Journal".

Siti Rayhani Fadhila, Lina Ninditya. 2016. (Dampak Dari Tidak Menyusui Di Indonesia). Sustainable Development Goals (SDGs).

Nur Halimah, Irna. 2010. (Cakupan Pemberian ASI Eksklusif Pada Bayi 0-6 Bulan). Humas Dinas Kesehatan Kota Bogor.

Nuraini. 2017. (Separuh Bayi Di Indonesia Tidak Dapat ASI Eksklusif). Direktur Jenderal Kesehatan Masyarakat Kementerian Kesehatan Anung Sugihantono. 